\title{
Proceeding
}

Supplementary Issue: Autumn Conferences of Sports Science. Costa Blanca Sports Science Events, 18-19 December 2020. Alicante, Spain.

\section{Level of physical activity of Peruvian university students during confinement}

\author{
LUZ ARELIS MORENO-QUISPE $\triangle$, CYNTHIA MILAGROS APAZA-PANCA, ANTHONY PAUL TAVARA- \\ RAMOS, JOYCE MAMANI-CORNEJO
}

Faculty of Hotel and Tourism Administration, National University of Frontera, Sullana, Peru

\begin{abstract}
Physical activity contributes to the health and well-being of students because of the physical, psychological, and social benefits it provides (especially during confinement). The objective was to identify the level of physical activity of college students during confinement by COVID-19. It is a descriptive and cross-sectional study conducted from March to July 2020. A population of 931 students enrolled in the Universidad Nacional de Frontera, Sullana-Peru, and a sample of 270 participated. The international physical activity questionnaire (IPAQ) was used. Of the total participants, $32 \%$ were men and $68 \%$ women, $51 \%$ resided in urban areas and $49 \%$ in rural areas. The level of physical activity was low in $20 \%$ of the students, moderate in $29 \%$ and high in $51 \%$ of the students respectively. Of the total, $13 \%$ were diagnosed with COVID-19, of which $2.6 \%$ had low levels of physical activity, $5.2 \%$ moderate and $5.5 \%$ high. $28.1 \%$ of the students had physical complaints associated with COVID-19 symptoms. It is concluded that during the confinement, the university students presented a high level of physical activity, mostly women from rural areas rather than urban areas, where the level of physical activity was low.

Keywords: Complementary educational services; Sports services; Student behaviour; Rural women; Rural students; COVID-19.

Cite this article as:

Moreno-Quispe, L.A., Apaza-Panca, C.M., Tavara-Ramos, A.P., \& Mamani-Cornejo, J. (2021). Level of physical activity of Peruvian university students during confinement. Journal of Human Sport and Exercise, 16(2proc), S763-S768. doi:https://doi.org/10.14198/ihse.2021.16.Proc2.62

Corresponding author. Faculty of Hotel and Tourism Administration, National University of Frontera, Sullana, Peru. https://orcid.org/0000-0003-1332-5739

E-mail: Imoreno@unf.edu.pe

Abstract submitted to: Autumn Conferences of Sports Science. Costa Blanca Sports Science Events, 18-19 December 2020. Alicante, Spain.

JOURNAL OF HUMAN SPORT \& EXERCISE ISSN 1988-5202

(c) Faculty of Education. University of Alicante

doi:10.14198/jhse.2021.16.Proc2.62
\end{abstract}




\section{INTRODUCTION}

On March 6, 2020 in Lima, Peru, the first confirmed case of coronavirus disease (COVID-19) was made public and on March 19 of the same year, the first death was confirmed. On March 11, 2020, the World Health Organization (WHO) declared a state of pandemic (WHO, 2020), thus becoming a public health issue (Jung \& Jun, 2020; Nishiura et al., 2020; Xie \& Chen, 2020). In response, many governments have chosen to implement mandatory social isolation under national regulations (Ayala et al., 2018; Harapan et al., 2020; Palacios Cruz et al., 2020), a decision that is shared by most epidemiological experts given the successful experience in China (Jimenez-Pavon et al., 2020; Mukhtar, 2020; Valero-Cedeño et al., 2020).

On March 15, the Peruvian government decreed a state of emergency and an order of compulsory social isolation (compulsory confinement) for 15 days at the national level (PCM, 2020), including days later curfew and successive extensions (PCM, 2020). On May 22, 2020, there were 111,698 people infected and 3,244 deaths in Peru. This new disease (COVID-19) has revealed in a raw and real way, the terrible sanitary situation of Peru.

Confinement is considered the best option to protect health. However, those most vulnerable to COVID-19 (those over 65 and those with severe heart disease, chronic lung disease, diabetes, obesity, and chronic liver or kidney disease) are negatively impacted by sedentary behaviour. Consequently, it is important to maintain a healthy lifestyle and, in particular, the practice of physical exercise (Rodriguez et al., 2020).

The WHO defines physical activity as any bodily activity, which leads to corresponding energy consumption. These include activities performed during play, work, travel, household chores or recreational activities. Although exercise should not be confused with physical activity, as exercise is a subcategory of physical activity, where physical movements are planned, structured and repetitive, aiming to improve or maintain one or more components of physical fitness (WHO., 2018).

According to (Martinez-Hita, 2020), non-compliance with the recommendation for physical activity is greater in the female gender $(70.1 \%)$ than in the male $(56.1 \%)$ and is also greater in the adolescent population $(69.9 \%)$ than in the child population (56.1\%).

Physical inactivity is the fourth most important risk factor for death rate worldwide, and this has a significant impact on the general health of the world's population, on the prevalence of noncommunicable diseases (e.g., cardiovascular diseases, diabetes, or cancer), and on their risk factors, such as hypertension, excess blood glucose, or overweight (WHO., 2010). Inactivity is a growing global health problem in developed countries and is considered a predictor of morbidity and mortality (WHO, 2020).

To reduce the spread of COVID-19 and not expose the university community to the disease, several universities around the world (including universities in underdeveloped countries like Peru) have taught academic activities virtually, rather than in-person. This has involved reformulating the complementary educational services offered by the university (health-topic service, psychology, volunteering, culture and sport) to the online form.

For this reason, the Universidad Nacional de Frontera, by Resolution of the Organizing Committee No. 1052020-UNF/CO, dated May 4, 2020, modified the 2020 work plan of the sports service to help student athletes maintain their physical condition and maintain a healthy life during the pandemic. However, not all athletic service activities impacted the student's prolonged stay at home. It is unclear what level of physical activity 
college students have engaged in during confinement and whether the rural or urban population has engaged in more physical activity.

Therefore, the objective of this study was to identify the level of physical activity of college students during confinement by COVID-19.

\section{METHODS}

\section{Research design}

A descriptive and cross-sectional study was conducted through a non-experimental design (Hernández, Fernández, \& Baptista, 2010).

\section{Participants}

A population of 931 university students enrolled in the National University of Frontera, Piura-Peru, participated, to whom complementary educational services such as sports were directed. A simple random probabilistic sampling was carried out and a sample of 270 students was obtained; under conditions of social isolation required by COVID-19.

\section{Instruments}

The International Physical Activity Questionnaire (IPAQ) was used with a scale of 7 indicators (Ipaq, 2005).

\section{Procedure}

The instrument was applied from March to July 2020. Each participant declared informed consent along with the online questionnaire, due to the conditions of mandatory social isolation in Peru. All data were treated according to the Declaration of Helsinki and its subsequent revisions, as well as data protection regulations. SPSS software version 23.0 was used for data processing and analysis.

\section{RESULTS}

Table 1. Physical activity levels of university students.

\begin{tabular}{lcccc}
\hline Gender & Low level & Moderate level & High level & Total \\
\hline Male & $12(4 \%)$ & $21(8 \%)$ & $53(20 \%)$ & $86(32 \%)$ \\
Woman & $43(16 \%)$ & $56(21 \%)$ & $85(31 \%)$ & $184(68 \%)$ \\
\hline Zone of residence & \multicolumn{5}{|l}{} \\
\hline Rural & $20(7.4 \%)$ & $41(15.2 \%)$ & $71(26.3 \%)$ & $132(48.9 \%)$ \\
Urban & $35(13 \%)$ & $36(13.3 \%)$ & $67(24.8 \%)$ & $138(51.1 \%)$ \\
\hline Diagnostic positive for COVID-19 19 & & \\
\hline Yes & $7(2.6 \%)$ & $14(5.2 \%)$ & $15(5.5 \%)$ & $36(13.3 \%)$ \\
No & $48(17.8 \%)$ & $63(23.3 \%)$ & $123(45.6 \%)$ & $234(86.7 \%)$ \\
\hline Physical discomfort and symptoms of COVID-19 & & \\
\hline Yes & $15(5.6 \%)$ & $25(9.3 \%)$ & $36(13.3 \%)$ & $76(28.1 \%)$ \\
No & $40(14.8 \%)$ & $52(19.3 \%)$ & $102(37.8 \%)$ & $194(71.9 \%)$ \\
\hline
\end{tabular}

The age of the participants was between 18-24 years. Of the total number of participants $32 \%$ were men and $68 \%$ women. $51 \%$ resided in urban areas and $49 \%$ in rural areas. The level of physical activity was low in $20 \%$ of the students, moderate in $29 \%$ and high in $51 \%$ of the students respectively. Of the total number of students, $13.3 \%$ were diagnosed with COVID-19, of which $2.6 \%$ had low, $5.2 \%$ moderate and $5.5 \%$ high 
levels of physical activity. $28.1 \%$ had physical complaints and symptoms associated with COVID-19, but these students were not diagnosed (Table 1).

\section{DISCUSSION}

During the confinement generated by COVID-19's disease, students have experienced a prolonged stay in their home, and possibly less energy expenditure from sitting, lying down, or doing their activities. In addition, the habit of playing games, watching television, and using mobile devices may have increased in students (Chen et al., 2020). Our study has limitations because we did not collect these variables, but $13.3 \%$ of students were diagnosed with COVID-19 and had a level of physical activity during confinement.

According to (Camacho-Cardenosa et al., 2020), the level of physical exercise developed at home can have a positive effect on student behaviour. However, the present study observed that there are more Peruvian students residing in urban areas than in rural areas. Those who reside in rural spaces develop physical activity at a moderate (15.2\%) and high (26.3\%) level compared with urban students.

Likewise, our study shows that women perform physical activity at a moderate $(21 \%)$ and high (31\%) level, that men ( $8 \%$ and $20 \%$ respectively), these results differ from the report of (Martinez-Hita, 2020), which indicates an increase in physical activity in the male gender than female; this difference possibly because more women participated in our study.

On the other hand, (Blair, 2009) points out that physical activity to maintain and improve health should be seen as a public policy for the general population and not just a recommendation for children and adolescents. Furthermore, it should be approached from a comprehensive perspective (educational, health, labour, transportation, etc.) during confinement and when returning to the new normalcy to engage in physical activity, exercise and sport without increased risk of catching COVID-19.

In this regard, it is a national policy to implement basic conditions of quality by Peruvian universities, this includes offering students the service of university canteen, transportation, social assistance, psychoeducation, sports, and encourage physical activity to reduce the risk of dropping out of college. However, during the pandemic, most of these services were suspended and sports service activities have been reduced essentially to the acquisition of goods and services, so encouraging physical activity is an opportunity to mitigate stress, anxiety and panic in the face of non-attendance academic activities during COVID-19.

Under this health uncertainty, we agree with some authors who argue that maintaining routines of physical activity and exercise should be a major strategy during periods of confinement because of its benefits on the immune system, cardiovascular disease, and in the psychosocial sphere (Chen et al., 2020; Hall et al., 2020).

According to (Aucancela-buri \& Bravo-Navarro, 2020), applying the IPAQ questionnaire to students at the Catholic University of Cuenca, Ecuador; high and moderate physical activity levels decreased during the pandemic when compared to the same levels before the pandemic, based on the sex and age of the students. Only students in the Physical Culture Education program maintained high levels of physical activity, highlighting the need for healthy habits among students not involved in physical education.

On the other hand (Ugidos et al., 2014), they applied to the students at the National University of La Matanza, Argentina; the Global Physical Activity Questionnaire (GPAQ) and a survey related to health habits, 
perception of happiness and other demographic variables. Their results indicate that students with a high level of physical activity were those who attended university on a day shift, did not smoke, did not consume alcohol or drugs, did not work, did not have children or a stable partner, and had an average socioeconomic level. In our study, we did not consider these variables, but a future study related to these issues and the implementation of physical activities by the university during the pandemic would be desirable.

\section{CONCLUSIONS}

It is concluded that during the confinement the university students presented a high level of physical activity; mostly women from rural areas rather than from urban areas, where the level of physical activity was low. The university should encourage physical activity on a permanent basis.

\section{REFERENCES}

Aucancela-buri, F. N., \& Bravo-navarro, W. H. (2020). Physical activity in university students before and during the COVID-19 pandemic. Pol. Con. 5(11), 163-176.

Ayala, A., Pujol, R., \& Abellán, A. (2018). Prevalence of homebound older people in Spain. Medicina de Familia. SEMERGEN, 44(8), 562-571. https://doi.org/10.1016/i.semerg.2018.07.001

Blair, S. N. (2009). Physical inactivity: The biggest public health problem of the 21st century. British Journal of Sports Medicine, 43(1), 1-2. https://doi.org/10.1016/s1440-2440(07)70066-x

Camacho-Cardenosa, A., Camacho-Cardenosa, M., Merellano-Navarro, E., Trapé, Á. A., \& BrazoSayavera, J. (2020). Influence of physical activity during outbreak on psychological states in adults in the COVID-19 pandemic: a study protocol. Revista Española de Salud Publica, 94, 1-9.

Chen, P., Mao, L., Nassis, G. P., Harmer, P., Ainsworth, B. E., \& Li, F. (2020). Coronavirus disease (COVID-19): The need to maintain regular physical activity while taking precautions. Journal of Sport and Health Science, 9(2), 103-104. https://doi.org/10.1016/i.jshs.2020.02.001

Hall, G., Laddu, D. R., Phillips, S. A., Lavie, C. J., \& Arena, R. (2020). A tale of two pandemics: How will COVID-19 and global trends in physical inactivity and sedentary behavior affect one another? Progress in cardiovascular diseases, S0033-0620(20)30077-3. Advance online publication. https://doi.org/10.1016/i.pcad.2020.04.005

Harapan, H., Itoh, N., Yufika, A., Winardi, W., Keam, S., Te, H., Megawati, D., Hayati, Z., Wagner, A. L., \& Mudatsir, M. (2020). Coronavirus disease 2019 (COVID-19): A literature review. Journal of Infection and Public Health. https://doi.org/10.1016/J.JIPH.2020.03.019

Hernández, S., Fernández, C., \& Baptista, L. (2010). Metodología de la investigación (5ta.ed.). México D.F.: McGraw Hill.

Ipaq. (2005). Guidelines for Data Processing and Analysis of the International Physical Activity Questionnaire ( IPAQ).

Jiménez-Pavón, D., Carbonell-Baeza, A., \& Lavie, C. J. (2020). Physical exercise as therapy to fight against the mental and physical consequences of COVID-19 quarantine: Special focus in older people. Progress in Cardiovascular Diseases. https://doi.org/10.1016/i.pcad.2020.03.009

Jung, S. J., \& Jun, J. Y. (2020). Mental health and psychological intervention amid COVID-19 outbreak: Perspectives from South Korea. Yonsei Medical Journal, 61(4), 271-272. https://doi.org/10.3349/ymi.2020.61.4.271

Martínez-Hita, F. J. (2020). Propuestas activas en Educación Física durante el confinamiento por el COVID-19. Lecturas: Educación Física y Deportes. 25(266), 2-13. https://doi.org/10.46642/efd.v25i266.2178 
Mukhtar S. (2020). Mental Health and Psychosocial Aspects of Coronavirus Outbreak in Pakistan: Psychological Intervention for Public Mental Health Crisis. Asian journal of psychiatry 51, 102069. https://doi.org/10.1016/i.app.2020.102069

Nishiura, H., Jung, S., Linton, N. M., Kinoshita, R., Yang, Y., Hayashi, K., Kobayashi, T., Yuan, B., \& Akhmetzhanov, A. R. (2020). The Extent of Transmission of Novel Coronavirus in Wuhan, China, 2020. Journal of Clinical Medicine, 9(2), 330. https://doi.org/10.3390/jicm9020330

Palacios Cruz, M., Santos, E., Velázquez Cervantes, M. A., \& León Juárez, M. (2020). COVID-19, a worldwide public health emergency. COVID-19, una emergencia de salud pública mundial. Revista clinica española, 221(1), 55-61. Advance online publication. https://doi.org/10.1016/i.rce.2020.03.001

Presidency of the Council of Ministers. (March 15, 2020). Supreme Decree Nº 044-2020-PCM. Supreme Decree declaring a state of national emergency due to the serious circumstances affecting the life of the nation as a result of the outbreak of COVID-19. El Peruano Official Newspaper, pp.10-13. Retrieved from: https://busquedas.elperuano.pe/download/url/decreto-supremo-que-declaraestado-de-emergencia-nacional-po-decreto-supremo-n-044-2020-pcm-1864948-2

Presidency of the Council of Ministers. (April 23rd, 2020). Supreme Decree N075-2020-PCM. Supreme Decree extending the state of national emergency due to the serious circumstances affecting the life of the nation as a result of COVID-19. El Peruano Newspaper, pp. 2-4. Retrieved from: https://busquedas.elperuano.pe/download/url/decreto-supremo-que-prorroga-el-estado-deemergencia-naciona-decreto-supremo-n-075-2020-pcm-1865780-1

Rodríguez, M. Á., Crespo, I., \& Olmedillas, H. (2020). Exercising in times of COVID-19: what do experts recommend doing within four walls? Revista Española de Cardiologia, 73(7), 527-529. https://doi.org/10.1016/j.recesp.2020.04.002

Ugidos, G. P., Laíño, F. A., Zelarayán, J., \& Márquez, S. (2014). Physical activity and health habits in Argentinian undergraduates. Nutricion Hospitalaria. https://doi.org/10.3305/nh.2014.30.4.7641

Valero-Cedeño, N. J., Mina-Ortiz, J. B., Veliz-Castro, T. I., Merchán-Villafuerte, K. M., \& Perozo-Mena, A. J. (2020). COVID-19: The new pandemic with many lessons and new challenges. Narrative Review. Kasmera, 48(1 PG-48102042020-48102042020). https://doi.org/10.5281/zenodo.3745322

WHO. (2010). Global Recommendations on Physical Activity for Health. Switzerland: World Health Organization. Retrieved from: https://apps.who.int/iris/bitstream/handle/10665/44441/9789243599977_spa.pdf?ua=1

WHO. (February 23rd, 2018). World Health Organization. Retrieved from: https://www.who.int/es/newsroom/fact-sheets/detail/physical-activity

WHO. (March 11, 2020). World Health Organization. Retrieved from: https://www.redaccionmedica.com/secciones/sanidad-hoy/coronavirus-pandemia-brote-de-COVID19-nivel-mundial-segun-oms-1895

WHO. (2020). World Health Organization, Scientific charter. 155(4), 7753.

Xie, M., \& Chen, Q. (2020). Insight into 2019 novel coronavirus - An updated interim review and lessons from SARS-CoV and MERS-CoV. International journal of infectious diseases: IJID: official publication of the International Society for Infectious Diseases, 94, 119-124. https://doi.org/10.1016/i.jij. 2020.03.071

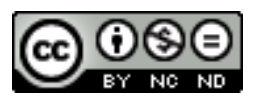

This work is licensed under a Attribution-NonCommercial-NoDerivatives 4.0 International (CC BY-NC-ND 4.0). 